\title{
The accuracy of ridge mapping procedure in determining the alveolar ridge width
}

\author{
Athraa A Ahmed B.D.S. (1) \\ Salwan Y. Bede B.D.S., F.I.B.M.S. ${ }^{(2)}$
}

\begin{abstract}
Background: Post-extraction alveolar ridge resorption is unavoidable phenomenon ending with insufficient ridge width. Measuring the physical dimensions of the available bone before implant surgery is an important aspect of diagnosis and treatment planning. Bone height can be calculated from radiographs, while bucco-lingual ridge width can be measured by conventional tomography, CT scanning and ridge mapping.

Radiographic techniques have certain disadvantages. Therefore the ridge mapping technique was used as an option for determining alveolar ridge width.

The purpose of this study was to compare the validity of alveolar ridge width measurements obtained with ridge mapping technique before surgical flap reflection against direct caliper measurement following surgical exposure of the bone.

Materials and Methods: This prospective observational clinical study included 21 patients; 9 males (42.9\%) and 12 females (57.1\%) with mean age of 40.8. A vacuum formed acrylic stent was fabricated for each subject. The stent provided two buccal/lingual pairs of consistent measurement points to provide a reference of measurement for each implant site located 3 and $6 \mathrm{~mm}$ from the crest of alveolar soft tissue. Measurements $(n=216)$ were made at 54 implant sites, the measurements obtained from the two techniques were compared and then accuracy of these methods was assessed. The mean, standard deviation, standard error of mean were calculated and subjected to statistical analysis using Student's unpaired t- test, values $<0.05$ were considered statistically significant.

Results: There was no statistically significant difference between ridge mapping technique and intra-operative measurement in determining alveolar ridge width.

Conclusion: The ridge mapping technique is a useful method in determining alveolar ridge width for its exactitude, low cost, the immediate result and no need of radiation.
\end{abstract}

Keywords: alveolar ridge width, ridge mapping. (Received: 10/9/2018; Accepted: 1/10/2018)

\section{INTRODUCTION}

Nowadays, dental implants (DIs) are a reliable treatment to replace lost teeth. However, placing DI is not an isolated event; it is the result of a cautious pre-surgical planning to fulfill the esthetic and functional expectations of patients. Assessment of the bucco-lingual dimension of the osseous ridge is needed for proper treatment planning. ${ }^{(1)}$

Conventional and computerized tomographic imaging modalities have a significant advantage in that bucco-lingual imaging is possible. ${ }^{(2,3)}$

On the other hand, in a way to overcome conventional radiographic limitations, some clinical methods have been suggested to measure transversal alveolar bone like ridge mapping (RM) technique.

This technique involves penetrating the buccal and lingual mucosa down to the alveolar bone (following the administration of local anesthetic) with calipers designed for this purpose.

(1)Al Ramadi specialized dental center, Al Anbar province, Iraq.

(2)BDS, FIBMS, Assistant Professor, Department of Oral and Maxillofacial Surgery, College of Dentistry, University of Baghdad.
The pointed tips of the instrument penetrate the buccal and lingual soft tissue layers and measure the bucco-lingual width of the underlying bone. A series of measurements of the proposed implant site can be made prior to reflection of a mucoperiosteal flap. This technique has been advocated by Wilson ${ }^{(4)}$ and Traxler et al. ${ }^{(5)}$ as a convenient and reliable method for assessing the suitability of potential implant sites. This procedure is performed chair-side and provides instant information.

The direct caliper measurement following surgical exposure of alveolar bone of the ridge gives the most accurate measurement. ${ }^{(6,7)}$

The aim of this study is to determine the accuracy of ridge mapping technique by comparing the measurements obtained by ridge mapping with direct caliper measurements of the alveolar ridge bone width after surgical exposure. 


\section{MATERIALS AND METHODS}

This prospective observational study included 21 patients, who attended the Department of Oral and Maxillofacial surgery at the College of Dentistry, University of Baghdad, for dental implant treatment to replace single or multiple missing teeth during the period extending from November 2017 to August 2018.

The inclusion criteria were:

1) Patients $\geq 18$ years of age including both genders presenting with single or multiple missing teeth in the maxillary and mandibular arches for at least 6 months after extraction (delayed implant placement protocol) and good oral hygiene.

2) Patients with no history of any systemic disease that could interfere with normal healing or inability to withstand surgery such as uncontrolled Diabetes Mellitus, bleeding disorders or history of chemotherapy or radiotherapy for the head and neck region.

The exclusion criteria included:

1) Presence of acute/chronic infection or local pathological condition in the proposed implant zone.

2) Parafunctional habits such as severe bruxism and clenching.

3) Patients with limited mouth opening to a degree that precludes easy handling and instrumentation.

Every Patient was informed about the procedures and the nature of the research, and those who agreed to participate signed an informed consent. The process started with an impression taken using condensation silicone (heavy body) impression material to form the diagnostic cast. The proposed implant sites and distribution were carefully evaluated on the cast and marked as reference points on the crest of the ridge in reference to the adjacent teeth, then 2 points were marked on the labial and palatal/lingual aspects of the ridge; the first point (point 1) at $3 \mathrm{~mm}$ from the reference point and the second point (point 2) at $6 \mathrm{~mm}$.

The surgical stent was fabricated on the diagnostic cast using vacuum former and Biostar acrylic sheet $2.0 \mathrm{~mm}$ thickness covering reference points, points 1 , points 2 and a few adjacent teeth. The points 1 and 2 were visible via the stent through the transparent acrylic resin material, then they were transferred to the stent by drilling guide holes large enough to accommodate the bone caliper tips.

After administration of local anesthesia the first clinical measurements were done by sterile bone caliper, the surgical stent was immersed in an antiseptic Povidone-Iodine solution and was placed in the area to be measured; the tips of the bone caliper were inserted into the guide holes, penetrating through the soft tissue until there was contact with bone and the measurements were recorded in millimeters, (Fig.1)

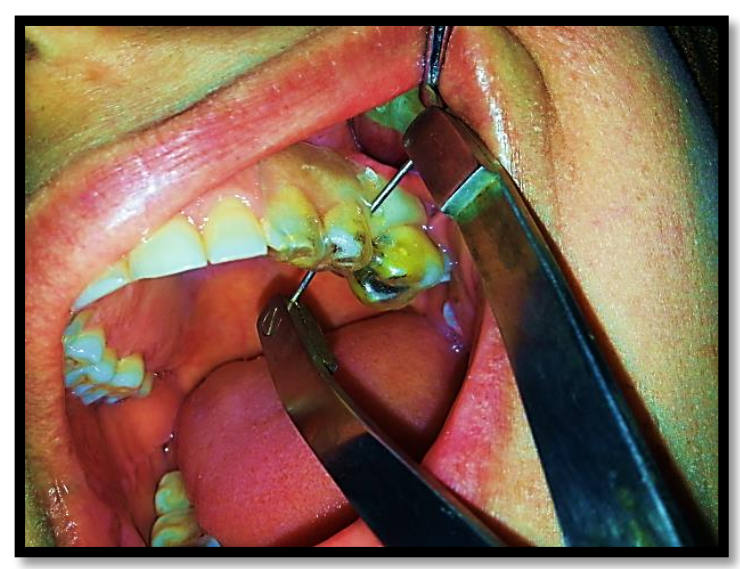

Figure 1: Pre-operative ridge mapping

After ridge mapping the stent was removed from the patient's mouth and returned into antiseptic Povidone-Iodine solution, then a three-sided mucoperiosteal flap consisting of a mid-crestal incision in addition to two vertical releasing incisions reflected. After flap reflection and exposure of the alveolar bone, the stent was relocated and the ridge width was measured directly on the exposed bone at the guide holes using the ridge mapping caliper device as described previously. The surgical stent was removed and the implant site preparation and installation of dental implants proceeded as per the manufacturer instructions.

All the reading of alveolar ridge width obtained from the ridge mapping and direct caliper measurement were then tabulated and compared. Descriptive statistical analysis included calculation of mean, standard deviation and standard error of mean and inferential analysis included using Student t-test for two independent means.

\section{RESULTS}

Twenty-one patients with a mean age $( \pm$ SD) of $40.8( \pm 16.7)$ years participated in this study and received 54 dental implants, they consisted of 9 males (42.9\%) and 12 females (57.1\%). According to the results obtained from 216 measurements that were made at the implant placement sites, the mean \pm SD of the alveolar ridge width for point 1 that was obtained from ridge mapping technique (pre-operative measurement) and intra-operative measurement after alveolar bone exposure was $0.333 \pm 0.752$ 
$\mathrm{mm}$ and $0.630 \pm 1.248 \mathrm{~mm}$ respectively and $3.833 \pm 0.927 \mathrm{~mm}$ and $4.019 \pm 1.107 \mathrm{~mm}$ respectively for point 2 .

The differences between the two measurements at both points were statistically not significant, as shown in Table 1.

Table 1: Descriptive and inferential analysis of ridge mapping (pre-operative) and direct caliper measurement (intra-operative) at point 1 and point 2

\begin{tabular}{|l|l|l|l|l|}
\hline & $\begin{array}{l}\text { Pre- } \\
\text { operat } \\
\text { ive } \\
\text { Point } \\
\mathbf{1}\end{array}$ & $\begin{array}{l}\text { Intra- } \\
\text { operat } \\
\text { ive } \\
\text { Point } \\
1\end{array}$ & $\begin{array}{l}\text { Pre- } \\
\text { operat } \\
\text { ive } \\
\text { Point } \\
\mathbf{2}\end{array}$ & $\begin{array}{l}\text { Intra- } \\
\text { operat } \\
\text { ive } \\
\text { Point } \\
\mathbf{2}\end{array}$ \\
\hline $\begin{array}{l}\text { No. of } \\
\text { measurem } \\
\text { ents }\end{array}$ & 54 & 54 & 54 & 54 \\
\hline Mean & 0.333 & 0.630 & 3.833 & 4.019 \\
\hline SD & 0.752 & 1.248 & 0.927 & 1.107 \\
\hline SE & 0.102 & 0.170 & 0.126 & 0.151 \\
\hline Min & 0.000 & 0.000 & 2.000 & 1.000 \\
\hline Max & 4.000 & 4.000 & 5.000 & 6.000 \\
\hline t-test & \multicolumn{2}{|c|}{1.494} & \multicolumn{2}{|c|}{0.943} \\
\hline p-value & 0.138 (N.S) & \multicolumn{2}{|c|}{0.348 (N.S) } \\
\hline
\end{tabular}

S.D. = standard deviation. S.E. = standard Error.

Min. $=$ minimum. Max. $=$ maximum .

N.S. =not significant.

\section{DISCUSSION}

In all phases of clinical dentistry, careful planning and diagnosis result in a more predictable outcome. ${ }^{(8)}$ The placement of dental implants requires meticulous planning and careful surgical procedures.

The contour of the residual bone must be evaluated prior to implant placement in order to assure proper implant positioning. (9) The measuring of ridge width can be accomplished using ridge-mapping calipers. The ridge-mapping procedure has the advantage of being simple to use and avoids exposure of the patient to radiation.

The results obtained from this study support the use of ridge-mapping procedure for the evaluation of alveolar ridge width, which is in keeping with Wilson ${ }^{(4)}$ in 1989 and Traxler et al. (5) in 1992, who suggested that ridge mapping is a convenient and reliable method for assessing suitability of potential implant sites.

Ten Bruggenkate et al. in $1994{ }^{(6)}$ using another ridge-mapping instrument in 60 subjects and 176 maxillary implant sites, compared the preoperative measurements (ridge mapping) to measurements following mucoperiosteal flap reflection (direct caliper measurements) and demonstrated that there was no significant difference between the two methods, without the use of any stent to identify the measurement locations. Chen et al., in their study in $2008^{(10)}$, made a similar observation.

Other studies, however, reported different results; Perez et al. ${ }^{(11)}$ found an average of $3.6 \pm$ $1 \mathrm{~mm}$ less than that obtained by direct measurement, they explained this difference by the fact that the application of excessive pressure when caliper points passed through soft tissue and bone could lead to perforation of the cortical bone and underestimation of the actual ridge width.

Allen and smith (7) reported a significant difference between the two methods and they observed a notable tendency to overestimate the bone width, probably due to the fact that the caliper may not completely penetrate the overlying mucosa down to bone, such a problem can arise if the overlying mucosa is particularly thick. They also maintained that underestimation of bone width may be caused by squeezing the beaks of the caliper too tightly, as the bone in this area is markedly cancellous, excessive pressure on the caliper may cause the beaks to penetrate through the outer cortical layer of bone. Some observations were made in this study that may limit the benefits of RM; the presence of a dehiscence in the alveolar ridge, which was observed following flap reflection, most measurements that were made at points 1 recorded $0 \mathrm{~mm}$, some difficulty was encountered in fitting the palatal aspect of the stent following mucoperiosteal flap reflection and in measuring of the mandibular alveolar ridge because of straight shank of ridge mapping device.

The main limitation of this study is its small sample size, however it can be concluded that ridge mapping technique proved to be reliable method to detect the alveolar ridge width.

\section{REFERENCES}

1. Simon BI, Von Hagen S, Deasy MJ, Faldu M, Resnansky D. Changes in alveolar bone height and width following ridge augmentation using bone graft and membranes. J Periodontol 2000; 71: 1774-1791.

2. Eckerdal, O. \& Kvint, S. Presurgical planning for osseointegrated implants in the maxilla. Int $\mathbf{J}$ Oral Maxillofac Surg 1986; 15: 722-726.

3. Schwarz, M., Rothman, S.L., Chafetz, N. \& Rhodes, M. Computed tomography in dental implant surgery. Dent. Clin. North Am. 1989; 33: 557-597. 
4. Wilson, D.J. Ridge mapping for determination of alveolar ridge width. Int $\mathbf{J}$ Oral Maxillofac Implants 1989; 4: 41-43.

5. Traxler, M., Ulm, C., Solar, P. \& Lill, W. Sonographic measurement versus mapping for determination of residual ridge width. J Prosthet Dent 1992; 67: 358-361.

6. Ten Bruggenkate CM, de Rijcke TB, Kraaijenhagen HA, Oosterbeek HS. Ridge mapping. Implant Dent 1994; 3: $179-82$.

7. Allen F, Smith DG. An assessment of the accuracy of ridge mapping in planning implant therapy for the anterior maxilla. Clin Oral Implants Res 2000; 11: 34-8.

8. Engelman MJ, Sorensen JA, Moy P. Optimum placement of osseointegrated implants. J Prosthet Dent 1988; 59: 467-73.
9. Boudrias P. Evaluation of the osseous edentulous ridge (i.e. Ridge mapping): Probing technique using a measuring guide. Dent Chron Assoc Prosthodontists Quebec 2003; 40: 301-2.

10. Chen LC, Lundgren T, Hallström H, Cherel F. Comparison of different methods of assessing alveolar ridge dimensions prior to dental implant placement. J Periodontol 2008; 79: 401-5.

11. Perez LA, Brooks SL, Wang HL, Eber RM. Comparison of linear tomography and direct ridge mapping for the determination of edentulous ridge dimensions in human cadavers. Oral Surg Oral Med Oral Pathol Oral Radiol Endod 2005; 99: 748-54.

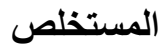

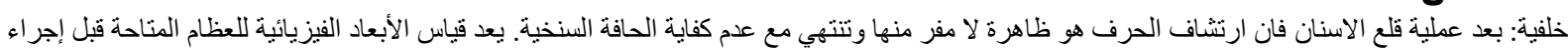

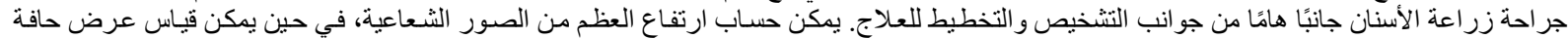

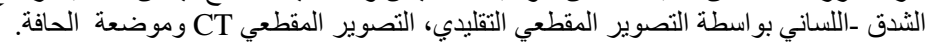

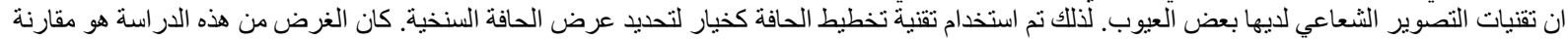

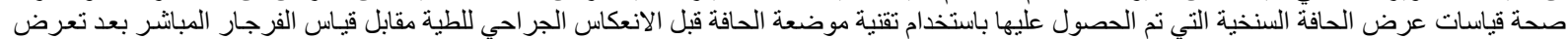

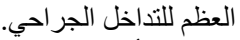
المو اد و الأساليب: شملت هذه الدر اسة السريرية المرتقبة 21 مريضا. 9 ذكور (42.9٪) و12 إناث (57.1٪) بمتوسط عمر 40.8. نم تصنيع دعامة أكريليك مكونة

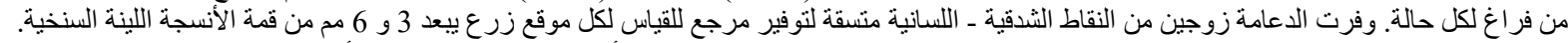

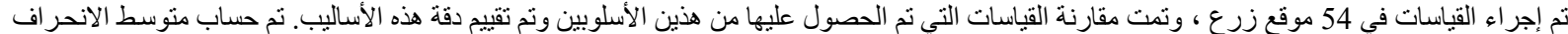

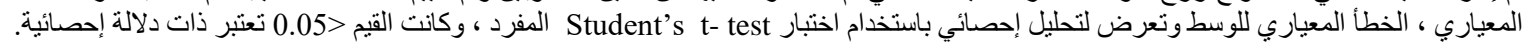

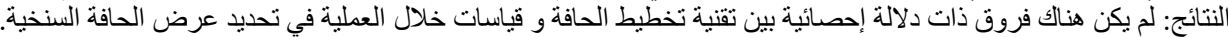

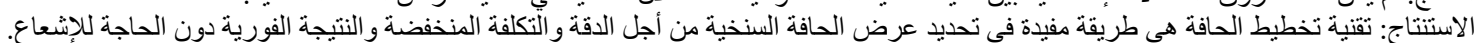
كلمات البحث: عرض الحنة الحافة السنخية ، تخطيط الحافة.
} 